\title{
Cholangiocarcinoma Prognosis Varies over Time Depending on Tumor Site and Pathology
}

\author{
Rena Kaneko $^{1,2}$, Yuzuru Sato ${ }^{2}$, Yasuki Kobayashi ${ }^{1}$
}

1) Department of Public

Health, Graduate School of

Medicine, The University of

Tokyo, Tokyo, Japan

2) Department of

Gastroenterology,

Organization of Occupational

Health and Safety.

Kanto Rosai Hospital,

Kanagawa, Japan
Address for correspondence:

Rena Kaneko

211-8510 Kizukisumiyoshi-

cho 1-1, Nakahara-Ku,

Kawasaki City,

Kanagawa, Japan

rena@kantoh.johas.go.jp

\section{ABSTRACT}

Background: Cholangiocarcinoma is a relatively rare cancer that is difficult to diagnose and has a poor prognosis. Currently, knowledge concerning its etiology, tumor localization, and pathological features remains limited. The present study aimed to clarify the clinico-epidemiologic nature of cholangiocarcinoma with its clinical subtypes using the largest regional cancer registry in Japan.

Methods: Using a regional cancer registry in Kanagawa prefecture, Japan, we estimated three-year and five-year survival rates of cholangiocarcinoma patients, who were classified into two groups: intrahepatic (i-CCA) and extrahepatic cholangiocarcinoma (e-CCA) cases. The hazard ratio for each subtype, including pathological tissue type and tumor site, was calculated.

Results: During the period from 1976 to 2013, 14,287 cases of cholangiocarcinoma were identified. The prognosis markedly improved after 2006, when a new type of chemotherapy for cholangiocarcinoma was introduced in Japan. Patients with i-CCA were more likely to be younger, and less likely to undergo surgery than those with e-CCA. The prognosis of cases with i-CCA was poor compared to that of patients with e-CCA. Conclusion: In Japan, i-CCA was more likely to develop in younger people and to have a poor prognosis. The prognosis of both i-CCA and e-CCA cases markedly improved after 2006. The present study describes clinico-epidemiological features of cholangiocarcinoma that may be useful for determining therapeutic strategies for this disease.

Key words: cholangiocarcinoma - bile duct cancer - epidemiology - survival - adenocarcinoma.

Abbreviations: CI : confidence interval; DCO: death-certificate-only; e-CCA: extrahepatic cholangiocarcinoma; i-CCA: intrahepatic cholangiocarcinoma; HR: hazard ratios.

\section{INTRODUCTION}

Cholangiocarcinoma is a cancer with a poor prognosis that arises from the cholangiocytes lining the biliary tree. Diagnosing cholangiocarcinoma is difficult and this cancer is very often fatal at the time of diagnosis due to its late clinical presentation and the absence of an effective therapeutic strategy, except for complete surgery [1]. According to the 10th revision of the International Statistical Classification of Diseases and Related Health Problems (ICD-10), cholangiocarcinoma includes intrahepatic bile duct cancer (C221), extrahepatic bile duct cancer (C240), and papillary cancer (C241). These three cancer types show different sensitivities to treatment and therefore require different therapeutic procedures.

Globally, it is well known that morbidity and mortality rates for cholangiocarcinoma are increasing $[2,3]$; regional differences that originate from rural risk factors are present [4-7]. The understanding of the cell of origin, well-established risk factors, molecular pathways and interactions has increased, and advances in surgical and nonsurgical treatments for cholangiocarcinoma have resulted in improved outcomes [8-12].

Even though such progress has been reported, most clinical trials have been performed without accurate analyses of subtype profiles, such as analyzing tumor site or its pathogenesis and, therefore, the evaluation of outcomes for specific subgroups of patients with cholangiocarcinoma is totally inadequate. In particular, studies focusing on the survival rates of various tumor sites or different pathological tissue types over time are lacking. 
We therefore examined the clinical and epidemiological characteristics of cholangiocarcinoma as well as the prognosis of patient subtypes according to the tumor site and pathology over time, using a large-scale cancer registry in Japan.

\section{METHODS}

\section{Kanagawa Regional Cancer Registry}

Kanagawa Prefecture is a neighbouring prefecture of Tokyo, and is the second largest in Japan, with a population of about nine million. The Prefecture started its own Regional Cancer Registry in 1970, with the accumulated number of cases being approximately 990,000 by December 31, 2013. Because the Tokyo Prefecture has only had a registry of cancer cases since 2012 and has therefore not yet accumulated substantial data, the Kanagawa Regional Cancer Registry is presently the largest regional cancer registry in Japan. Details on the cancer registry system in Japan have been reported elsewhere [13]. Data was collected from neoplasm registration sheets reported by each diagnosing hospital or from clinics and death certificates of residents in Kanagawa Prefecture. The Kanagawa Prefectural Cancer Center collected and consolidated the data into anonymous formats and made these available for academic and administrative purposes.

Accumulated data include the following items: 1) personal identification code, 2) method of registry entry, 3) diagnosing institution, 4) sex, 5) date of birth, 6) date of diagnosis, 7) local government code for the patient's home address, 8) ICD-10 code for disease name, 9) ICD-O-3 code for pathology, 10) initial or recurrent tumour, 11) therapeutic strategy (very brief), 12) operative procedure (if any), 13) date of death, 14) cause of death, 15) date of last follow-up, and 16) TNM classification and pathological grade according to ICD-O-3 in diagnosed patients. The reporting of TNM classifications became mandatory in 2005 .

All information was collected by persons trained in Japan by the Surveillance, Epidemiology, and End Results (SEER) program of the National Cancer Institute in the US. Information was updated every year from vital statistics and death certificates. Previous versions of pathological codes were transformed to the latest versions through standardized regulations consistent with changes in coding practices for cholangiocarcinoma. The proportion of death-certificate-only (DCO) cases in the whole database was $18.2 \%$ by the end of 2013 [14].

\section{Subject and classification method}

We obtained clinical data relating to gastrointestinal cancers between June 15, 1954 and December 30, 2013 in an anonymous format under a research agreement with the Kanagawa Prefectural Cancer Center. From such data, intrahepatic bile duct (C221), extrahepatic bile duct (C240), and papillary cancers (C241), according to ICD-10, were extracted and included in this study. Gall bladder cancer (C230) was excluded from the analysis, based on current guidelines for the diagnosis and treatment of cholangiocarcinoma [15].

In order to determine the trend in patient survival rates throughout the entire analysis period, the three-year survival rate of patients was calculated every two years. Because the number of registrations for cholangiocarcinoma before 1975 was small, we excluded these data.

With regard to the five-year survival rate, we divided the whole study period into Period 1 (from 1976 until 2006), before the introduction of new regimens of chemotherapy (such as gemcitabine, tegafur/gimeracil/oteracil or cisplatin) for the treatment of cholangiocarcinoma in Japan, and Period 2 (from 2006 to 2013), after the approval of new regimens.

Regarding the location of tumors, C221 was defined as an intrahepatic cholangiocarcinoma (i-CCA), and C240 and C241 were defined as extrahepatic cholangiocarcinomas (e-CCA).

In cases in which a pathological tissue code was available according to ICD-O-3, we defined adenocarcinomas as shown in Supplementary Table I, based on the World Health Organization International Histological Classification of Tumors and the International Agency for Research on Cancer and Rare Care Net Information Network on Rare Cancers.

Regarding the age of onset, young-onset was defined in cases younger than 65 years of age at the time of diagnosis, while old-onset was defined as 65 years or older.

Because of a broad diversity of direct causes of death from cholangiocarcinoma, overall death was chosen for calculating hazard ratios (HR).

\section{Statistical analysis}

A $\chi$ square test was performed for differences between percentages of baseline characteristics. The five-year survival rate was estimated using the Kaplan-Meier method. Cox proportional hazard models were used to calculate adjusted HR for overall death. P values $<0.05$ or $<0.01$ were considered to be statistically significant. Analyses were performed using STATA/MP14.0 software (Stata-Corp LP, College Station, TX).

This study was approved by the Ethics Committee of the University of Tokyo (No. 10891), and the Japan Organization of Occupational Health and Safety, Kanto Rosai Hospital (No. 2014-34).

\section{RESULTS}

The total number of patients with gastrointestinal cancer registered in the Kanagawa Prefecture Regional Cancer Registry from 1954 to 2013 was 498,983 . Of these, patients with cholangiocarcinoma comprised 14,287 cases from 1976 to 2013. The details are as follows: the numbers of intrahepatic cholangiocarcinoma (C221), extrahepatic cholangiocarcinoma (C240), and carcinoma of the ampulla of Vater (C241) cases were 3,369 (23.6\%), 9,285 (65.0\%), and 1,633 (11.4\%), respectively (Table I).

The numbers of males and females were 8,345 (58.4\%) and 5,942 (41.6\%), respectively. Cases of i-CCA and e-CCA comprised 3,369 (23.6\%) and 10,918 (76.4\%), respectively. In Period 1, 10,041 (70.3\%) cases were included, while in Period 2, 4,246 (29.7\%) cases were recognized (Table I). The average age of patients with cholangiocarcinoma was 71.4 years $( \pm$ $11.5)$, and the average age at death was 72.8 years $( \pm 11.4)$. Data concerning the presence/absence of treatment, except for surgical procedures, was available in 10,837 cases. 
Table I. Baseline characteristics of cholangiocarcinoma patients

\begin{tabular}{|c|c|c|c|c|c|c|}
\hline & \multirow[t]{2}{*}{ Overall $\dagger$} & \multicolumn{3}{|c|}{ ICD10 } & \multicolumn{2}{|c|}{$\begin{array}{c}\text { Location of } \\
\text { cholangiocarcinoma }\end{array}$} \\
\hline & & $\mathrm{C} 221$ & $\mathrm{C} 240$ & $\mathrm{C} 241$ & Intrahepatic & Extrahepatic \\
\hline Number (\%) & $14287(100)$ & 3369 (23.6) & $9285(65.0)$ & $1633(11.4)$ & 3369 (23.6) & $10918(76.4)$ \\
\hline \multicolumn{7}{|l|}{ Age at diagnosis, years } \\
\hline$(\text { Mean } \pm S D)^{\ddagger}$, years & $71.4 \pm 11.5$ & $69.6 \pm 11.4$ & $72.4 \pm 11.4$ & $69.0 \pm 11.2$ & $69.6 \pm 11.4$ & $71.9 \pm 11.4$ \\
\hline \multicolumn{7}{|l|}{ Age at death } \\
\hline$(\text { Mean } \pm S D)^{\ddagger}$ & $72.8 \pm 11.4$ & $70.6 \pm 11.4$ & $73.8 \pm 11.3$ & $72.0 \pm 11.7$ & $70.6 \pm 11.4$ & $73.5 \pm 11.3$ \\
\hline Median of OS & 185 & 142 & 183 & 402 & 142 & 201 \\
\hline IQR (25\%:75\%) & $(62: 475)$ & $(54: 359)$ & $(61: 462)$ & $(137: 939)$ & $(65: 520)$ & $(54: 359)$ \\
\hline \multicolumn{7}{|l|}{ Gender } \\
\hline Male & 8345 (58.4) & $2028(60.2)$ & $5344(57.6)$ & $973(59.6)$ & $2028(60.2)$ & $6317(57.9)$ \\
\hline Female & $5942(41.6)$ & $1341(39.8)$ & $3941(42.4)$ & $660(40.4)$ & $1341(39.8)$ & $4601(42.1)$ \\
\hline \multicolumn{7}{|l|}{ Period ${ }^{\S}$} \\
\hline Period 1 & $10041(70.3)$ & 2355 (69.9) & $6621(71.3)$ & $1065(65.2)$ & 2355 (69.9) & $7686(70.4)$ \\
\hline Period 2 & $4246(29.7)$ & $1014(30.1)$ & $2664(28.7)$ & $568(34.8)$ & $1014(30.1)$ & $3232(29.6)$ \\
\hline \multicolumn{7}{|l|}{ Operation } \\
\hline Yes & $5911(41.4)$ & 964 (28.6) & $3852(41.5)$ & $1095(67.1)$ & $964(28.6)$ & 4947 (45.3) \\
\hline No & $8376(58.6)$ & 2405 (71.4) & $5433(58.5)$ & $538(33.0)$ & 2405 (71.4) & $5971(54.7)$ \\
\hline \multicolumn{7}{|l|}{ Other treatment } \\
\hline Data available & $10837(75.9)$ & $2583(76.7)$ & $6815(73.4)$ & $1429(87.5)$ & $2593(77.0)$ & $8244(75.5)$ \\
\hline Chemotherapys & $2288(21.1)$ & $797(30.9)$ & $1276(18.7)$ & $215(15.0)$ & $797(30.7)$ & $1491(18.0)$ \\
\hline Radiation"s & $493(4.5)$ & $151(5.8)$ & $327(4.8)$ & $15(1.0)$ & $151(5.8)$ & $342(4.1)$ \\
\hline
\end{tabular}

\section{Three-year survival rate}

Figure 1 shows the temporal change in the three-year survival rate (every two years from 1976 to 2013). According to the data, the prognosis of patients appeared to improve with the introduction of new chemotherapeutic agents: the prognosis in $2009-2010$ was $40.9 \%$, significantly different from that in 2005-2006 (23.7\%), and 2007-2008 (28.4\%).

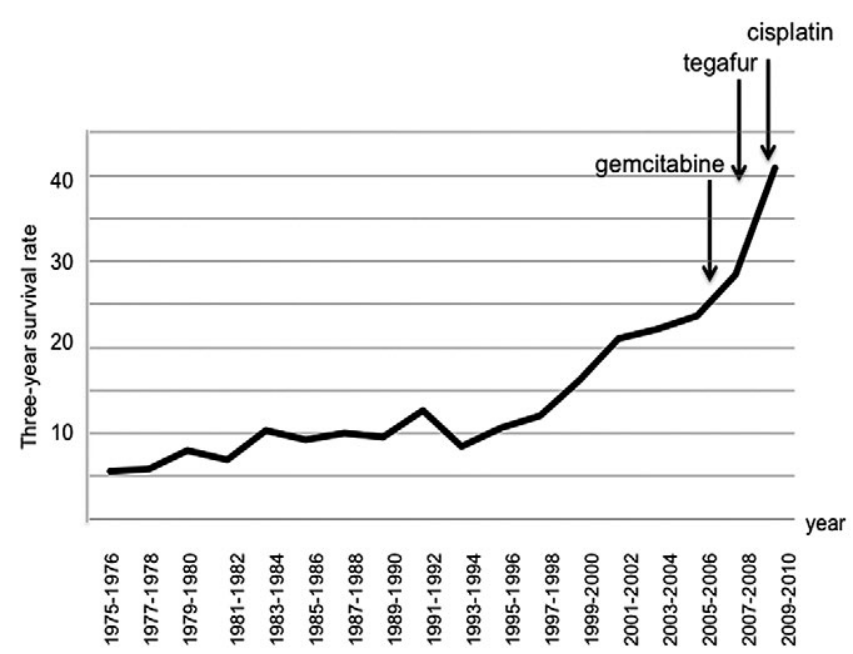

Fig. 1. Three-year survival rates were calculated every two years from 1976 to 2013. Arrows indicate the introduction of gemcitabine, tegafur, and cisplatin treatments.
Figure 2 shows five-year survival rates of i-CCA and e-CCA cases by period. The five-year survival rate of patients with i-CCA was higher in Period 2 (20.3\%) than in Period 1 (5.5\%), while that of patients with e-CCA also increased from Period $1(8.7 \%)$ to Period $2(29.4 \%)$. For both periods, the survival rate of patients with i-CCA was significantly lower than that of patients with e-CCA $(\mathrm{p}<0.01)$. The same trend was observed in analysis after the exclusion of cases with papillary cancer (C241).

\section{Pathology}

The number of cases in which pathological tissue was classified based on ICD-O-3 was 5,441. The distribution of patient characteristics in these cases is shown in Table II. Overall, comparing i-CCA and e-CCA cases, a significant difference was observed in the age of onset and whether patients underwent surgery; those patients with i-CCA were more likely to have young-onset $(\mathrm{p}<0.01)$ and less likely to have undergone surgery than those with e-CAA $(p<0.01)$. Regarding overall histopathological results, the proportion of nonadenocarcinoma cases was significantly higher in i-CCA than in e-CAA ( $p<0.02)$; however, this statistical difference disappeared when we examined the two periods separately. The details of non-adenocarcinoma cases in i-CCA were as follows: 10 patients with squamous cell carcinoma, 6 with undifferentiated, 6 with sarcoma, and 5 with neuroendocrine carcinoma, as well as 3 other cases. Among extrahepatic cholangiocarcinoma cases 
Table II. Distribution of cholangiocarcinoma with pathological information

\begin{tabular}{|c|c|c|c|}
\hline $\begin{array}{l}\text { Characteristics } \\
\text { Number (\%) }\end{array}$ & $\begin{array}{c}\text { Intrahepatic } \\
\text { cholangiocarcinoma }\end{array}$ & $\begin{array}{c}\text { Extrahepatic } \\
\text { cholangiocarcinoma }\end{array}$ & P-value \\
\hline \multicolumn{4}{|l|}{ Overall $(\mathrm{N}=5441)$} \\
\hline Gender & & & 0,74 \\
\hline Male & $894(63.6)$ & $2546(63.1)$ & \\
\hline Female & $512(36.4)$ & $1489(36.9)$ & \\
\hline Age of onset $\dagger$ & & & $<0.01^{* *}$ \\
\hline Old & 870 (61.9) & $2784(69.0)$ & \\
\hline Young & $536(38.1)$ & $1251(31.1)$ & \\
\hline Pathology & & & $<0.02^{*}$ \\
\hline Adenocarcinoma & $1376(97.9)$ & $3985(98.8)$ & \\
\hline Non-adenocarcinoma & $30(2.1)$ & $50(1.2)$ & \\
\hline Operation & & & $<0.01^{* *}$ \\
\hline Yes & $577(41.0)$ & $2594(64.3)$ & \\
\hline No & $829(58.9)$ & $1441(35.7)$ & \\
\hline \multicolumn{4}{|l|}{ Period $1(\mathrm{~N}=3088)$} \\
\hline Gender & & & 0.32 \\
\hline Male & 546 (62.6) & $1345(60.7)$ & \\
\hline Female & $326(37.4)$ & $871(39.3)$ & \\
\hline Age of onset & & & $0.02^{*}$ \\
\hline Old & $507(58.0)$ & $1389(62.7)$ & \\
\hline Young & $365(41.9)$ & $827(37.3)$ & \\
\hline Pathology & & & 0.12 \\
\hline Adenocarcinoma & $855(98.0)$ & $2189(98.8)$ & \\
\hline Non-adenocarcinoma & $17(1.2)$ & $27(1.2)$ & \\
\hline Operation & & & $<0.01^{* *}$ \\
\hline Yes & $367(42.1)$ & $1529(69.0)$ & \\
\hline No & $505(57.9)$ & $687(31.0)$ & \\
\hline \multicolumn{4}{|l|}{ Period $2(\mathrm{~N}=2353)$} \\
\hline Gender & & & 0.67 \\
\hline Male & $348(65.2)$ & $1201(66.0)$ & \\
\hline Female & $186(34.8)$ & $618(34.0)$ & \\
\hline Age of onset & & & $<0.01^{* *}$ \\
\hline Old & $363(68.0)$ & $1395(76.7)$ & \\
\hline Young & $171(32.0)$ & $424(23.3)$ & \\
\hline Pathology & & & 0.05 \\
\hline Adenocarcinoma & $521(97.6)$ & $1796(98.7)$ & \\
\hline Non-adenocarcinoma & $13(2.4)$ & $23(1.3)$ & \\
\hline Operation & & & $<0.01^{* *}$ \\
\hline Yes & $210(39.3)$ & $1065(58.6)$ & \\
\hline No & $324(60.7)$ & $754(41.5)$ & \\
\hline
\end{tabular}

${ }^{+}$Young-onset cholangiocarcinoma is defined as patients under 65 years of age; ${ }^{*} \mathrm{P}$-value $<0.05^{\star}$ or $<0.01^{\star *}$ were considered to be statistically significant.

there were 17 patients with squamous cell carcinoma, 12 with neuroendocrine carcinoma, 7 with small cell carcinoma, 5 with sarcoma, 5 with a carcinoid tumor, and one undifferentiated, as well as 3 other cases, respectively. There was no significant difference in the distribution of gender between i-CCA and e-CCA cases.
Table III shows HRs adjusted for other factors, including Periods 1 or 2, age of onset, gender, location of the cholangiocarcinoma, histopathology, and whether surgery was performed. In model 1, HRs were analyzed using 5,361 adenocarcinoma cases only. The HR for i-CCA cases was significantly higher than that for e-CCA cases (HR 1.39, 


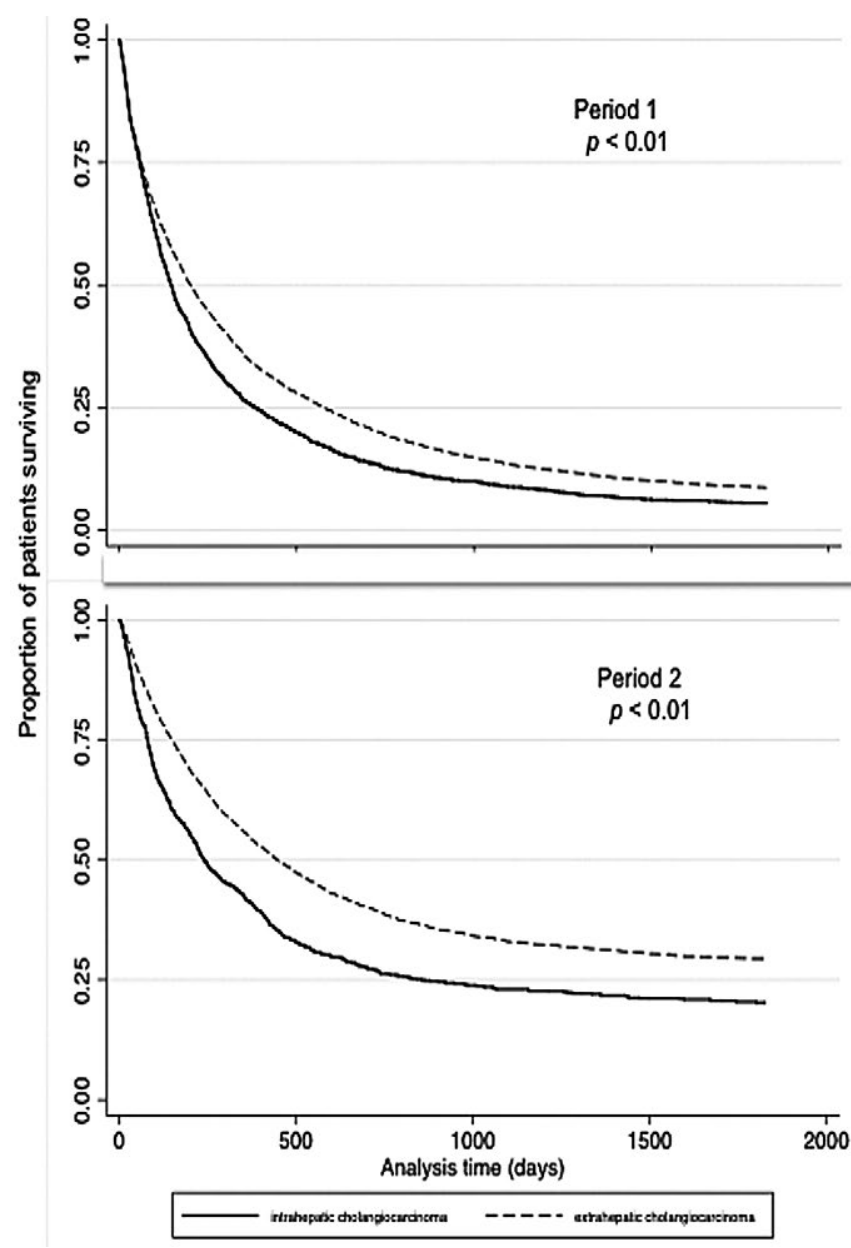

Fig. 2. Kaplan-Meier survival curves for overall survival between intrahepatic and extrahepatic cholangiocarcinoma cases in each period. Survival was estimated using the Kaplan-Meier method in patients with complete information on sex, age, location of bile duct cancer, and observation period, and with right censoring at the 5-year mark. P values were calculated from log-rank tests. With advances in chemotherapy, the survival rate improved for both intrahepatic and extrahepatic cholangiocarcinomas.

95\% CI 1.30-1.50). The HR for cases who had undergone surgery was significantly lower than that for those who had not undergone an operation (HR 0.52, 95\% CI 0.49-0.56). Model 2 shows HRs analyzed using 5,441 cases, including non-adenocarcinoma. When non-adenocarcinoma cases were included, the $\mathrm{p}$ values of each variable did not change. The HR for non-adenocarcinoma cases was significantly lower than that for adenocarcinoma cases (HR 0.71, 95\% CI 0.54-0.95).

\section{DISCUSSION}

Our study showed that the prognosis of cholangiocarcinoma markedly improved with the introduction of new chemotherapeutic agents. The prognosis was significantly different depending on tumor site and pathological tissue type.

In recent years, cholangiocarcinomas have been classified as intrahepatic, peri-hilar and distal $[12,16,17]$. However, reports concerning the outcome of treatment with anticancer drugs for these three types of cholangiocarcinoma are limited [18-20]. Five-year survival rates were found to be $20-32 \%, 30-42 \%$, and
18-54\% for intrahepatic, hilar, and distal cholangiocarcinomas, respectively [20-31]. The prognostic factors of resected cases are the presence of lymph node metastasis [23, 25, 28] or minute vascular invasion [16]. However, complete resection and adjuvant chemotherapy have improved the prognosis for all tumor sites [19, 20].

A couple of factors have made the clinico-epidemiological analysis of cholangiocarcinoma difficult. The first is the ambiguity in classifying tumor location, the topology of which was changed when moving from the second edition of the International Classification of Diseases for Oncology (ICD-O-2) to its third edition (ICD-O-3). Studying 3,350 cholangiocarcinoma cases between 1992 and 2000, Welzel et al. highlighted the misclassification between intrahepatic and extrahepatic cholangiocarcinoma in the SEER program [32]. In addition, it is often difficult to detect the original site of the tumor if the tumor stage is advanced on initial presentation $[16,32]$.

Using a large-scale cancer registry, we found that the survival rate of patients with cholangiocarcinoma markedly improved with the introduction of new chemotherapeutic agents. This indicated that the new chemotherapies immediately became popular in Japan and influenced the prognosis of such patients. Regarding the location of the tumor, i-CCA cases had a poorer prognosis than e-CCA throughout the entire period studied. This difference was noted both before and after the introduction of a new type of chemotherapy, probably due to the characteristics of the disease itself. In the case of patients with e-CCA, the presence of obstructive jaundice accelerates the diagnosis of this disease. In contrast, in patients with i-CCA, the disease progresses without any signs and symptoms resulting in a delay in its diagnosis [7]. The reasons for the difference in the prognosis between i-CCA and e-CCA cases may also originate from the type of surgery performed. In i-CCA cases, hepatectomy is generally undertaken and therefore residual liver function becomes an important prognostic factor [33]. In e-CCA cases, pancreatoduodenectomy is mostly indicated. If this procedure is successfully carried out, the resulting prognosis may be favorable $[15,34]$. Therefore, differences in the type of surgery undertaken may have also caused the difference observed in the prognosis of patients with the two types of cholangiocarcinomas.

It is also true that no clear evidence exists that chemotherapy confers any survival benefit to patients with all histologic subtypes of cholangiocarcinoma, because the number of variant cases is not substantial enough to undertake a meaningful statistical analysis $[24,35,36]$. Moreover, large-scale epidemiological studies do not exist with regard to differences in prognosis that may occur among cholangiocarcinoma cases with different histopathological aspects. Cholangiocarcinoma mostly consists of adenocarcinoma and a few other variants [37]. In this study, histopathological information was obtained for 5,441 cases, about one-third of the total cholangiocarcinoma cases studied. As we have previously reported, the proportions of young-onset and non-adenocarcinoma cases were significantly higher for i-CCA $[38,39]$. The current study also showed the same tendency. In addition, this study suggested that the prognosis for patients with adenocarcinoma was poorer than that for patients with non-adenocarcinoma. 
Table III. Hazard ratios for overall deaths adjusted for available confounders

\begin{tabular}{|c|c|c|c|c|}
\hline \multirow[b]{2}{*}{ Characteristics } & \multicolumn{2}{|c|}{ Hazard ratio $(95 \% \mathrm{CI})^{\dagger}$} & \multicolumn{2}{|c|}{ Hazard ratio $(95 \% \mathrm{CI})^{\dagger}$} \\
\hline & Model $1(n=5361)$ & P-value ${ }^{\S}$ & Model $2(n=5441)$ & P-value \\
\hline \multicolumn{5}{|l|}{ Period $\ddagger$} \\
\hline Period 1 & 1.00 (ref) & & 1.00 (ref) & \\
\hline Period 2 & $0.49(0.46-0.53)$ & $<0.01^{\star *}$ & $0.49(0.46-0.52)$ & $<0.01^{\star *}$ \\
\hline \multicolumn{5}{|l|}{ Age of onset } \\
\hline Old & $1.00(\mathrm{ref})$ & & 1.00 (ref) & \\
\hline Young & $0.87(0.82-0.94)$ & $<0.01^{* *}$ & $0.87(0.81-0.93)$ & $<0.01^{* *}$ \\
\hline \multicolumn{5}{|l|}{ Gender } \\
\hline Male & 1.00 (ref) & & 1.00 (ref) & \\
\hline Female & $1.02(0.96-1.09)$ & 0.41 & $1.02(0.96-1.09)$ & 0.43 \\
\hline \multicolumn{5}{|c|}{ Location of cholangiocarcinoma } \\
\hline Extrahepatic & 1.00 (ref) & & 1.00 (ref) & \\
\hline Intrahepatic & $1.39(1.30-1.50)$ & $<0.01^{* *}$ & $1.38(1.29-1.48)$ & $<0.01^{\star *}$ \\
\hline \multicolumn{5}{|l|}{ Operation } \\
\hline No & 1.00 (ref) & & 1.00 (ref) & \\
\hline Yes & $0.52(0.49-0.56)$ & $<0.01^{* *}$ & $0.52(0.49-0.55)$ & $<0.01^{\star *}$ \\
\hline \multicolumn{5}{|l|}{ Pathology } \\
\hline Adenocarcinoma & - & & 1.00 (ref) & \\
\hline Non-adenocarcinoma & - & - & $0.71(0.54-0.95)$ & $<0.02^{*}$ \\
\hline
\end{tabular}

${ }^{\dagger}$ Data analyzed by a Cox proportional hazards model between the variables of observation period, age, gender, location of cholangiocarcinoma, operation and pathology. Model 1 was analyzed using 5361 cases with adenocarcinoma only. Model 2 involved 5441 patients that included non-adenocarcinoma cases. ${ }^{*}$ Period: Period 1: 1976-2005, Period 2: 2006-2013; ${ }^{\circledR}$ P-value $<0.05^{\star}$ or $<0.01^{\star *}$ was considered to be statistically significant.

Since, for these analysis periods, chemotherapy may be the only difference in treatment strategies among adenocarcinoma and non-adenocarcinoma cases, adenocarcinoma may have been more strongly resistant to chemotherapy.

As for cholangiocarcinoma, obtaining pathological tissue is difficult as it is only available after surgery is performed. In many cases, cytology by endoscopic retrograde cholangiopancreatography (ERCP) is used for a diagnosis. Unfortunately, an ERCP cytodiagnosis often yields ambiguous results since it is mainly performed for the quick, rapid relief and suppression of infection and jaundice $[15,40]$. However, since the effectiveness of anti-cancer drugs depends on the histological nature of the disease, a pathological diagnosis is very important as shown in the current study. In addition, early diagnosis is required since non-adenocarcinomas, such as neuroendocrine tumors, may already be at an advanced stage at the time of diagnosis $[35,41]$.

Reasons why the age at onset as well as pathological tissue differed between i-CCA and e-CCA are considered as follows: known risk factors for cholangiocarcinoma include intrahepatic stones, liver fluke, biliary-duct cysts, and toxins. Differences in such risk factors between i-CCA and e-CCA may exist [42]. In addition to these environmental factors, host factors also influence carcinogenesis. The intrahepatic bile duct consists of cells of different origin, including cuboidal non-mucin-producing cholangiocytes, mucin-producing cholangiocytes and hepatic progenitor cells (HPCs) [43]. An i-CCA grows from such heterogeneous cells. The histological appearance is not uniform: a mixed type is seen in the small intrahepatic bile duct and a mucinous type is seen in the large intrahepatic bile duct $[33,44,45]$. In contrast, e-CCA originates from a single cell, and therefore tends to consist of a single mucinous adenocarcinoma [44].

In Japan, gemcitabine has been used as a standard chemotherapy for unresectable cholangiocarcinoma since 2006 while tegafur/gimeracil was approved in 2008. Although cisplatin was approved in 2011, it does not appear effective enough to bring on a radical cure [8]. Despite the rise in morbidity due to an aging population, the survival rate for patients with cholangiocarcinoma has clearly improved with the increasing availability of chemotherapy [33]. Additionally, continuous advances in surgical techniques and drainage technology for cholangitis have contributed to a better prognosis for cholangiocarcinoma. Overall, combined therapies using new techniques such as cholangiopancreatoscopy is expected to improve treatment and further enhance the prognosis of patients with cholangiocarcinoma.

TNM classifications were available for 1,902 cases and we calculated the HR for overall death after including this information. We defined cases in stages 1-3 as a reference. The HRs for the period, young-onset/old-onset, site of tumor, gender, adenocarcinoma/non-adenocarcinoma, operation, and TNM staging were 0.71 (95\% CI 0.54-0.96), 0.84 (95\% CI 0.73-0.91), 1.39 (95\% CI 1.22-1.59), 1.00 (95\% CI 0.86-1.13), 0.40 (95\% CI $0.20-0.80), 0.67$ (95\% CI $0.59-0.76)$ and 3.01 (95\% CI 2.63-3.44), respectively. Even though we included information on TNM, our main results were only slightly affected. 
Several limitations exist in this study. Firstly, with regard to selection bias, differences in mortality among sub-groups may exist. However, because DCO cases in this study were $18.2 \%$, which was less than the $20 \%$ reliability criterion of the cancer registry, this suggested that the precision of the overall survival estimates was high and that selection bias was minimal. Secondly, because of the nature of the database, we could not adjust for factors that were common risk factors for cholangiocarcinoma (viral hepatitis, primary sclerosing cholangitis, hepatolithiasis, smoking, occupation, and socioeconomic conditions) and therefore these factors may have been confounding with regard to the findings of the current study. Thirdly, little information on treatments existed. For example, we did not have detailed information about operation methods or chemotherapy regimens; therefore, we could not identify which therapies actually improved the prognosis of i-CCA and e-CCA cases after 2006. Such pivotal information should be collected in any future studies.

\section{CONCLUSION}

This study revealed two important findings. First, we found an obvious difference in prognosis between patients with intrahepatic or extrahepatic cholangiocarcinoma. Second, non-adenocarcinoma cases showed a better survival rate than adenocarcinoma cases. These results will be helpful in any future research and treatment of cholangiocarcinoma.

Conflicts of interest: The authors declare that they have no conflict of interest.

Authors' contribution: R.K. collected and analyzed the data, and drafted the manuscript; Y.S. contributed to the study design; Y.K. supervised the study. All the authors read and approved the final version to be published.

Supplementary material: To access the supplementary material visit the online version of the J Gastrointestin Liver Dis at http://www. jgld.ro/wp/archive/y2018/n1/a10 and http://dx.doi.org/10.15403/ jgld.2014.1121.271.kak

\section{REFERENCES}

1. Carriaga MT, Henson DE. Liver, gallbladder, extrahepatic bile ducts, and pancreas. Cancer 1995;75:171-190.

2. Ikeda A, Miyashiro I, Nakayama T, et al. Descriptive epidemiology of bile duct carcinoma in Osaka. Jpn J Clin Oncol 2013;43:1150-1155. doi: $10.1093 /$ jjco/hyt126

3. Khuntikeo N, Chamadol N, Yongvanit P, et al. Cohort profile: cholangiocarcinoma screening and care program (CASCAP). BMC Cancer 2015;15:459. doi:10.1186/s12885-015-1475-7

4. Sithithaworn P, Yongvanit P, Duenngai K, Kiatsopit N, Pairojkul C. Roles of liver fluke infection as risk factor for cholangiocarcinoma. J Hepatobiliary Pancreat Sci 2014;21:301-308. doi:10.1002/jhbp.62

5. Saengboonmee C, Seubwai W, Wongkham C, Wongkham S. Diabetes mellitus: Possible risk and promoting factors of cholangiocarcinoma: Association of diabetes mellitus and cholangiocarcinoma. Cancer Epidemiol 2015;39:274-278. doi:10.1016/j.canep.2015.04.002
6. Razumilava N, Gores GJ. Classification, diagnosis, and management of cholangiocarcinoma. Clin Gastroenterol Hepatol 2013;11:13-21.e1. doi:10.1016/j.cgh.2012.09.009

7. Khan SA, Thomas HC, Davidson BR, Taylor-Robinson SD. Cholangiocarcinoma. Lancet 2005;366:1303-1314. doi:10.1016/s01406736(05)67530-7

8. Valle J, Wasan H, Palmer DH, et al. Cisplatin plus gemcitabine versus gemcitabine for biliary tract cancer. N Engl J Med 2010;362:1273-1281. doi:10.1056/NEJMoa0908721

9. Okusaka T, Nakachi K, Fukutomi A, et al. Gemcitabine alone or in combination with cisplatin in patients with biliary tract cancer: a comparative multicentre study in Japan. Br J Cancer 2010;103:469-474. doi:10.1038/sj.bjc.6605779

10. Endo I, Gonen M, Yopp AC, et al. Intrahepatic cholangiocarcinoma: rising frequency, improved survival, and determinants of outcome after resection. Ann Surg 2008;248:84-96. doi:10.1097/ SLA.0b013e318176c4d3

11. Nagino M, Ebata T, Yokoyama Y, et al. Evolution of surgical treatment for perihilar cholangiocarcinoma: a single-center 34-year review of 574 consecutive resections. Ann Surg 2013;258:129-140. doi:10.1097/ SLA.0b013e3182708b57

12. Reding R, Buard JL, Lebeau G, Launois B. Surgical management of 552 carcinomas of the extrahepatic bile ducts (gallbladder and periampullary tumors excluded). Results of the French Surgical Association Survey. Ann Surg 1991;213:236-241.

13. Okamoto N. A history of the cancer registration system in Japan. Int J Clin Oncol 2008;13:90-96. doi:10.1007/s10147-008-0759-1

14. Government of Kanagawa prefecture. Annual report of Kanagawa Cancer Registry 40th edition. In: UICC 2016 Annual Report. May 31, 2017.

15. Khan SA, Davidson BR, Goldin RD, et al. Guidelines for the diagnosis and treatment of cholangiocarcinoma: an update. Gut 2012;61:16571669. doi:10.1136/gutjnl-2011-301748

16. Ercolani G, Dazzi A, Giovinazzo F, et al. Intrahepatic, peri-hilar and distal cholangiocarcinoma: Three different locations of the same tumor or three different tumors? Eur J Surg Oncol 2015;41:1162-1169. doi:10.1016/j.ejso.2015.05.013

17. Chou FF, Sheen-Chen SM, Chen CL, Chen YS, Chen MC. Prognostic factors of resectable intrahepatic cholangiocarcinoma. J Surg Oncol 1995;59:40-44. doi:10.1002/jso.2930590111

18. DeOliveira ML, Cunningham SC, Cameron JL, et al. Cholangiocarcinoma: thirty-one-year experience with 564 patients at a single institution. Ann Surg 2007;245:755-762. doi:10.1097/01.sla.0000251366.62632.d3

19. Kelley ST, Bloomston M, Serafini F, et al. Cholangiocarcinoma: advocate an aggressive operative approach with adjuvant chemotherapy. Am Surg 2004;70:743-748.

20. Murakami Y, Uemura K, Sudo T, et al. Prognostic factors after surgical resection for intrahepatic, hilar, and distal cholangiocarcinoma. Ann Surg Oncol 2011;18:651-658. doi:10.1245/s10434-010-1325-4

21. Shimada K, Sano T, Sakamoto Y, Esaki M, Kosuge T, Ojima H. Surgical outcomes of the mass-forming plus periductal infiltrating types of intrahepatic cholangiocarcinoma: a comparative study with the typical mass-forming type of intrahepatic cholangiocarcinoma. World J Surg 2007;31:2016-2022. doi:10.1007/s00268-007-9194-0

22. Konstadoulakis MM, Roayaie S, Gomatos IP, et al. Fifteen-year, single-center experience with the surgical management of intrahepatic cholangiocarcinoma: operative results and long-term outcome. Surgery 2008;143:366-374. doi:10.1016/j.surg.2007.10.010 
23. Uenishi T, Kubo S, Yamazaki O, et al. Indications for surgical treatment of intrahepatic cholangiocarcinoma with lymph node metastases. J Hepatobiliary Pancreat Surg 2008;15:417-422. doi:10.1007/s00534007-1315-5

24. Nakagohri T, Kinoshita T, Konishi M, Takahashi S, Gotohda N. Surgical outcome and prognostic factors in intrahepatic cholangiocarcinoma. World J Surg 2008;32:2675-2680. doi:10.1007/s00268-008-9778-3

25. Guglielmi A, Ruzzenente A, Campagnaro $\mathrm{T}$, et al. Intrahepatic cholangiocarcinoma: prognostic factors after surgical resection. World J Surg 2009;33:1247-1254. doi:10.1007/s00268-009-9970-0

26. Igami T, Nishio H, Ebata T, et al. Surgical treatment of hilar cholangiocarcinoma in the "new era": the Nagoya University experience. J Hepatobiliary Pancreat Sci 2010;17:449-454. doi:10.1007/s00534-009-0209-0

27. Hirano S, Kondo S, Tanaka E, et al. Outcome of surgical treatment of hilar cholangiocarcinoma: a special reference to postoperative morbidity and mortality. J Hepatobiliary Pancreat Sci 2010;17:455-462. doi:10.1007/s00534-009-0208-1

28. Lee SG, Song GW, Hwang S, et al. Surgical treatment of hilar cholangiocarcinoma in the new era: the Asan experience. J Hepatobiliary Pancreat Sci 2010;17:476-489. doi:10.1007/s00534-009-0204-5

29. Unno M, Katayose Y, Rikiyama T, et al. Major hepatectomy for perihilar cholangiocarcinoma. J Hepatobiliary Pancreat Sci 2010;17:463-469. doi:10.1007/s00534-009-0206-3

30. Woo SM, Ryu JK, Lee SH, et al. Recurrence and prognostic factors of ampullary carcinoma after radical resection: comparison with distal extrahepatic cholangiocarcinoma. Ann Surg Oncol 2007;14:3195-3201. doi:10.1245/s10434-007-9537-y

31. Hong SM, Pawlik TM, Cho H, et al. Depth of tumor invasion better predicts prognosis than the current American Joint Committee on Cancer $\mathrm{T}$ classification for distal bile duct carcinoma. Surgery 2009;146:250-257. doi:10.1016/j.surg.2009.02.023

32. Welzel TM, McGlynn KA, Hsing AW, O’Brien TR, Pfeiffer RM. Impact of classification of hilar cholangiocarcinomas (Klatskin tumors) on the incidence of intra- and extrahepatic cholangiocarcinoma in the United States. J Natl Cancer Inst 2006;98:873-875. doi:10.1093/jnci/djj234

33. Banales JM, Cardinale V, Carpino G, et al. Expert consensus document: Cholangiocarcinoma: current knowledge and future perspectives consensus statement from the European Network for the Study of
Cholangiocarcinoma (ENS-CCA). Nat Rev Gastroenterol Hepatol 2016;13:261-280. doi:10.1038/nrgastro.2016.51

34. Razumilava N, Gores GJ. Cholangiocarcinoma. Lancet 2014;383:2168 2179. doi:10.1016/s0140-6736(13)61903-0

35. Kihara Y, Yokomizo H, Urata T, Nagamine M, Hirata T. A case report of primary neuroendocrine carcinoma of the perihilar bile duct. BMC Surg 2015;15:125. doi:10.1186/s12893-015-0116-Z

36. Lee SY, Shia J, Kingham TP, Jarnagin WR. Carcinosarcoma of the bile duct: a case report and review of literature. Hepatobiliary Surg Nutr 2016;5:72-78. doi:10.3978/j.issn.2304-3881.2015.06.09

37. Nakanuma Y, Sato Y, Harada K, Sasaki M, Xu J, Ikeda H. Pathological classification of intrahepatic cholangiocarcinoma based on a new concept. World J Hepatol 2010;2:419-427. doi:10.4254/wjh.v2.i12.419

38. Kaneko R, Hagiwara $\mathrm{H}$, Hagiwara $\mathrm{H}$, et al. Clinical characteristics and exposure to organic solvents in young-onset cholangiocarcinoma cases from Rosai Hospital Group illness and career data base. Kanzo 2015;56:332-340. doi:10.2957/kanzo.56.332

39. Kaneko R, Nakazaki N, Tagawa T, et al. Preliminary analysis of labour effect on genesis of cholangiocarcinoma. Nihon Shokakibyo Gakkai Zasshi 2014;111:550-511. doi:10.11405/nisshoshi.111.510

40. Sugimoto S, Matsubayashi H, Kimura H, et al. Diagnosis of bile duct cancer by bile cytology: usefulness of post-brushing biliary lavage fluid. Endosc Int Open 2015;3:E323-E328. doi:10.1055/s-0034-1391666

41. Levenson RM Jr, Ihde DC, Matthews MJ, et al. Small cell carcinoma presenting as an extrapulmonary neoplasm: sites of origin and response to chemotherapy. J Natl Cancer Inst 1981;67:607-612. doi:10.1093/ jnci/67.3.607

42. Tyson GL, El-Serag HB. Risk factors for cholangiocarcinoma. Hepatology 2011;54:173-184. doi:10.1002/hep.24351

43. Lazaridis KN, LaRusso NF. The Cholangiopathies. Mayo Clin Proc 2015;90:791-800. doi:10.1016/j.mayocp.2015.03.017

44. Komuta M, Govaere O, Vandecaveye V, et al. Histological diversity in cholangiocellular carcinoma reflects the different cholangiocyte phenotypes. Hepatology 2012;55:1876-1888. doi:10.1002/hep.25595

45. Aishima S, Oda Y. Pathogenesis and classification of intrahepatic cholangiocarcinoma: different characters of perihilar large duct type versus peripheral small duct type. J Hepatobiliary Pancreat Sci 2015;22:94-100. doi:10.1002/jhbp.154 
Supplementary table I. Definition of cholangiocarcinoma pathologies.

Characteristics

Definition by ICD-O-3

$\begin{array}{ll}\text { adenocarcinoma }^{\dagger} & \text { Intrahepatic Bile Tract } \\ & 8160,8140-8141,8143,8147,8162,8190,8201,8210-8211 \\ & 8221,8230-8231,8255,8260-8263,8290,8310,8315,8320 \\ & 8323,8333,8380-8384,8430,8440-8441,8450,8480-8482 \\ & 8490,8500,8503-8504,8510,8512,8514,8525,8542 \\ & 8550-8551,8560,8562,8571-8576 \\ & \text { Extra Bile Tract } \\ & 8020-8022,8050,8140-8141,8143,8144,8147,8160,8162 \\ & 8190,8200,8201,8210-8211,8221,8230-8231,8251,8255 \\ & 8260-8263,8290,8310,8315,8320,8323,8333,8350, \\ 8380-8384,8430,8440-8441,8450,8480,8482,8490 \\ 8500,8503-8504,8510,8512,8514,8521,8525,8542,8550 \\ 8551,8560-8562,8570,8571-8576\end{array}$

${ }^{\dagger}$ Adenocarcinoma of the bile duct using Information Network on Rare Cancers

RARECARENet. 